$\underline{\text { Revised Manuscript No. cg050263a }}$

\title{
Self-assembled Octameric and Tetrameric Water Clusters Gather Luminescent Zinc(II) Complexes Around to Hydrogen-Bonded Framework Structures and Associated Fluorescence Modulation
}

\author{
Sanjib Das and Parimal K. Bharadwaj* \\ Department of Chemistry, Indian Institute of Technology, Kanpur 208016, India \\ E-mail: pkb@iitk.ac.in
}

\section{Supporting Information}

Table S1 Geometrical parameters for various hydrogen bonding interactions for 4 .

Figure S1 UV-Vis spectra of compound 1 (concentration $1 \times 10^{-5} \mathrm{M}$ ) in different solvent (JASCO, V-570, UV/VIS/NIR/ Spectrophotometer)

Figure S2 Fluorescence spectra of 1 (concentration $1 \times 10^{-6} \mathrm{M}$ ) in different solvent (PERKIN ELMER, LS50B, Luminescence Spectrometer)

Figure S3 Fluorescence spectra of 2 (concentration $1 \times 10^{-6} \mathrm{M}$ ) in different solvent (PERKIN ELMER, LS50B, Luminescence Spectrometer)

Figure S4 Uv-Vis spectra of compound 1 in different ratio (v/v) of water/ethanol mixture (JASCO, V-570, UV/VIS/NIR/ Spectrophotometer).

Figure S5 TGA spectra of compound 3.

Figure S6 X-ray powder diffraction spectra of compound 1: (a) hydrated condition (b) de-hydrated upon heating at $110{ }^{\circ} \mathrm{C}$ for $1 \mathrm{~h}$ and (c) re-hydrated condition.

Figure S7 X-ray powder diffraction spectra of compound 2: (a) hydrated condition (b) de-hydrated upon heating at $100{ }^{\circ} \mathrm{C}$ for $1 \mathrm{~h}$ and (c) re-hydrated condition.

Figure S8 FTIR spectra of compound 3.

Figure S9 A simplified view of the tetrameric water clusters in the crystal lattice of 3. 
Figure S10 A simplified view of the octameric water clusters in the crystal lattice of 4.

Figure S11 Building of the tetrameric water clusters in $\mathbf{3}$ viewed in the crystallographic $b c$ plan. Ethanol molecules are omitted and only carboxylate parts of the $d c a$ units are shown for clarity.

Figure S12 The mode of binding of octameric water clusters in 4 viewed approximately in the crystallographic $b c$ plan.

Figure S13 TGA spectra of compound 4.

Figure S14 FTIR spectra of compound 4.

Figure S15 FTIR spectra of compound 1.

Figure S16 FTIR spectra of compound 2.

Figure S17 Calculated XRD patter of compound 3 .

Figure S18 Calculated XRD patter of compound 4. 
Table S1. Geometrical parameters for various interactions found in $\mathbf{4}$

\begin{tabular}{|c|c|c|c|c|}
\hline Interaction & & $\begin{array}{c}\mathrm{D}^{a} \\
(\AA \stackrel{\AA}{ })\end{array}$ & $\begin{array}{r}\mathrm{d}^{b} \\
(\AA)\end{array}$ & $\begin{array}{c}\theta^{c} \\
\text { (deg.) }\end{array}$ \\
\hline \multirow{20}{*}{$\overline{\mathrm{C}-\mathrm{H} \cdots \mathrm{O}}$} & $\mathrm{O} 1 \cdots \mathrm{H} 12$ & $3.502(7)$ & $2.623(3)$ & $157.52(2)$ \\
\hline & $\mathrm{O} 1 \cdots \mathrm{H} 9$ & $3.412(7)$ & $2.596(5)$ & $146.77(2)$ \\
\hline & $\mathrm{O} 2 \cdots \mathrm{H} 13$ & $3.391(7)$ & $2.702(8)$ & 131.51(2) \\
\hline & $\mathrm{O} 1 \mathrm{~W} \cdots \mathrm{H} 24$ & $3.689(2)$ & $2.802(4)$ & $160.02(2)$ \\
\hline & 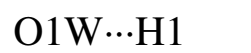 & $3.504(2)$ & $2.907(3)$ & $123.14(2)$ \\
\hline & $\mathrm{O} 1 \mathrm{~W} \cdots \mathrm{H} 10$ & $3.756(2)$ & $2.970(3)$ & $143.05(2)$ \\
\hline & $\mathrm{O} 1 \mathrm{~W} \cdots \mathrm{H} 2$ & $3.688(2)$ & $2.804(3)$ & $159.01(2)$ \\
\hline & O3W $\cdots \mathrm{H} 15$ & $3.609(2)$ & $2.759(3)$ & $152.60(2)$ \\
\hline & 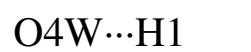 & $3.758(2)$ & $3.075(3)$ & 131.61(2) \\
\hline & $\mathrm{O} 4 \mathrm{~W} \cdots \mathrm{H} 22$ & $3.784(2)$ & 2.861(3) & $171.96(2)$ \\
\hline & $\mathrm{O} 4 \mathrm{~W} \cdots \mathrm{H} 25$ & $3.618(2)$ & $2.852(3)$ & $140.43(2)$ \\
\hline & 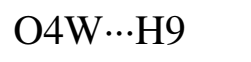 & $4.030(2)$ & $3.266(3)$ & $140.88(2)$ \\
\hline & $\mathrm{O} 1 \mathrm{~W} \cdots \mathrm{O} 2$ & $3.007(3)$ & & \\
\hline & 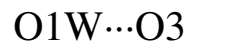 & $2.730(4)$ & & \\
\hline & $\mathrm{O} 3 \mathrm{~W} \cdots \mathrm{O} 4$ & $3.070(7)$ & & \\
\hline & $\mathrm{O} 4 \mathrm{~W} \cdots \mathrm{O} 1$ & $3.229(2)$ & & \\
\hline & $\mathrm{O} 1 \mathrm{~W} \cdots \mathrm{O} 2 \mathrm{~W}$ & $2.836(8)$ & & \\
\hline & $\mathrm{O} 1 \mathrm{~W} \cdots \mathrm{O}^{2} \mathrm{~W}^{\prime}$ & $2.873(2)$ & & \\
\hline & $\mathrm{O} 2 \mathrm{~W} \cdots \mathrm{O} 3 \mathrm{~W}$ & $2.727(3)$ & & \\
\hline & $\mathrm{O} 2 \mathrm{~W} \cdots \mathrm{O} 4 \mathrm{~W}$ & $2.961(3)$ & & \\
\hline
\end{tabular}

${ }^{a} \mathrm{D}$ is the distance between $\mathrm{C}$ or $\mathrm{O}$ and the acceptor (O-atom). ${ }^{b} \mathrm{~d}$ is the distance between $\mathrm{H}$ and the acceptor (O-atom). ${ }^{c} \theta$ is the angle at $\mathrm{H}$ in $\mathrm{C}-\mathrm{H} \cdots \mathrm{X}(\mathrm{X}=\mathrm{O}$-atom).

\section{Solid-state fluorescence measurements:}

A commercial spectrometer (SPEX, Fluorolog 3, Model FL3-22) was used to record the solid-state emission as well as excitation spectra of compound $\mathbf{1}$ - 4. The excitation light, from a $450 \mathrm{~W}$ Xenon lamp having a spot size dimention of $\sim 1 \mathrm{~mm} \mathrm{x}$ $12 \mathrm{~mm}$ was incident on the sample kept in a quartz cuvette with a path length of $10 \mathrm{~mm}$. The band pass for the emission monochromators was $2 \mathrm{~nm}$ and slapped through $1 \mathrm{~nm}$ while recording spectra. The integration time was kept 0.2 second. 


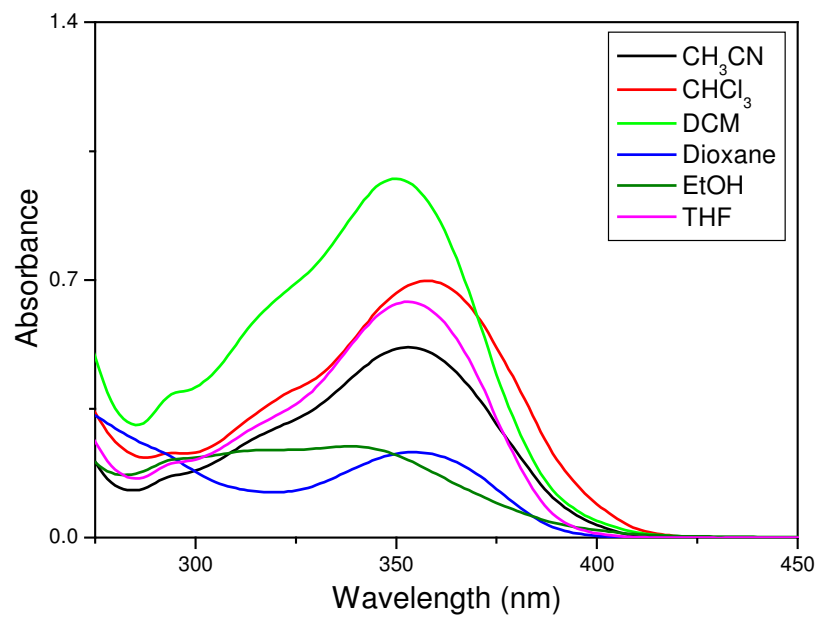

Figure S1. UV-Vis spectra of compound 1 (concentration $1 \times 10^{-5} \mathrm{M}$ ) in different solvent (JASCO, V-570, UV/VIS/NIR/ Spectrophotometer)

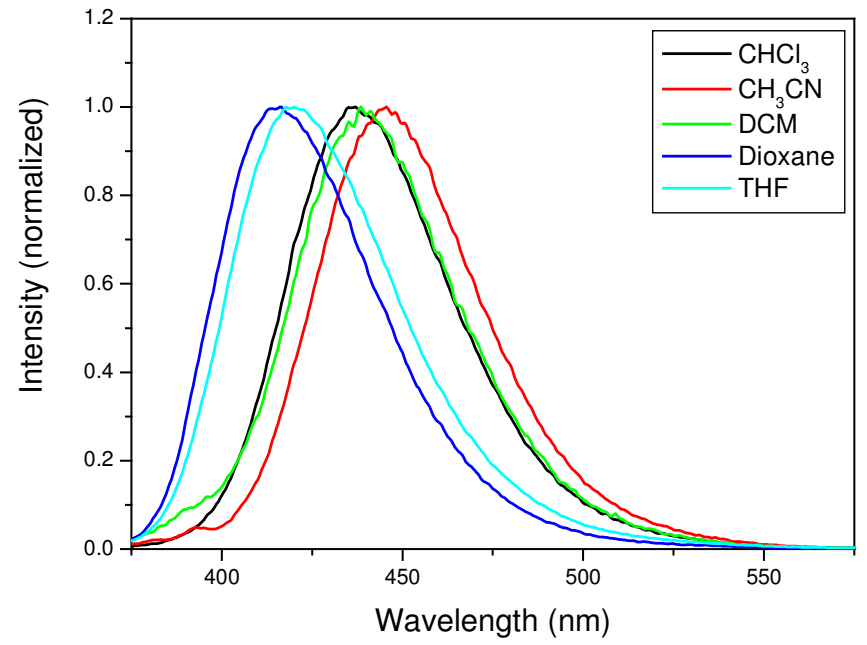

Figure S2. Fluorescence spectra of 1 (concentration $1 \times 10^{-6} \mathrm{M}$ ) in different solvent (PERKIN ELMER, LS50B, Luminescence Spectrometer) 


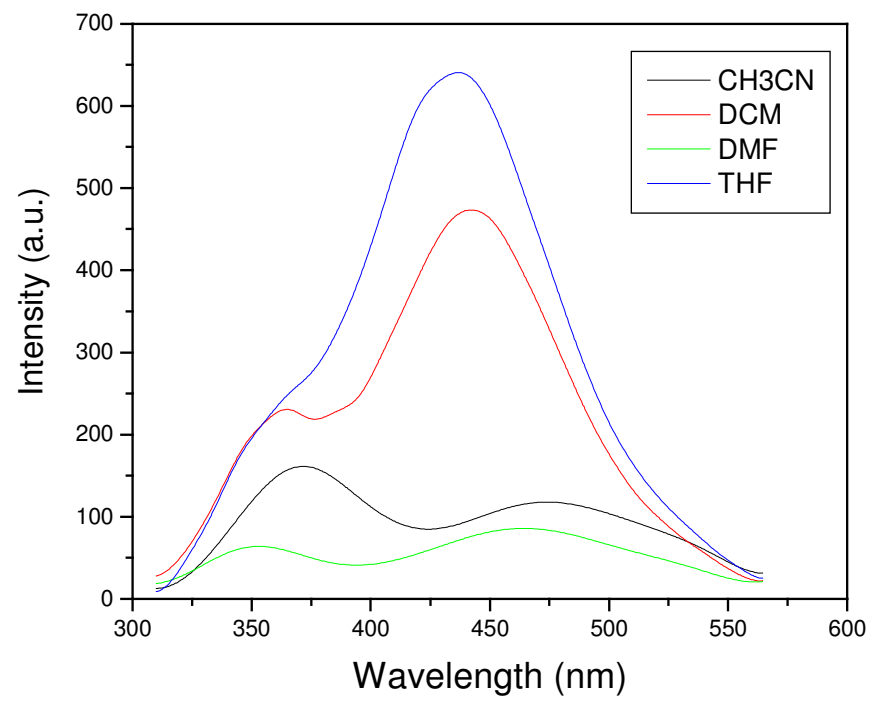

Figure S3. Fluorescence spectra of 2 (concentration $1 \times 10^{-6} \mathrm{M}$ ) in different solvent (PERKIN ELMER, LS50B, Luminescence Spectrometer)

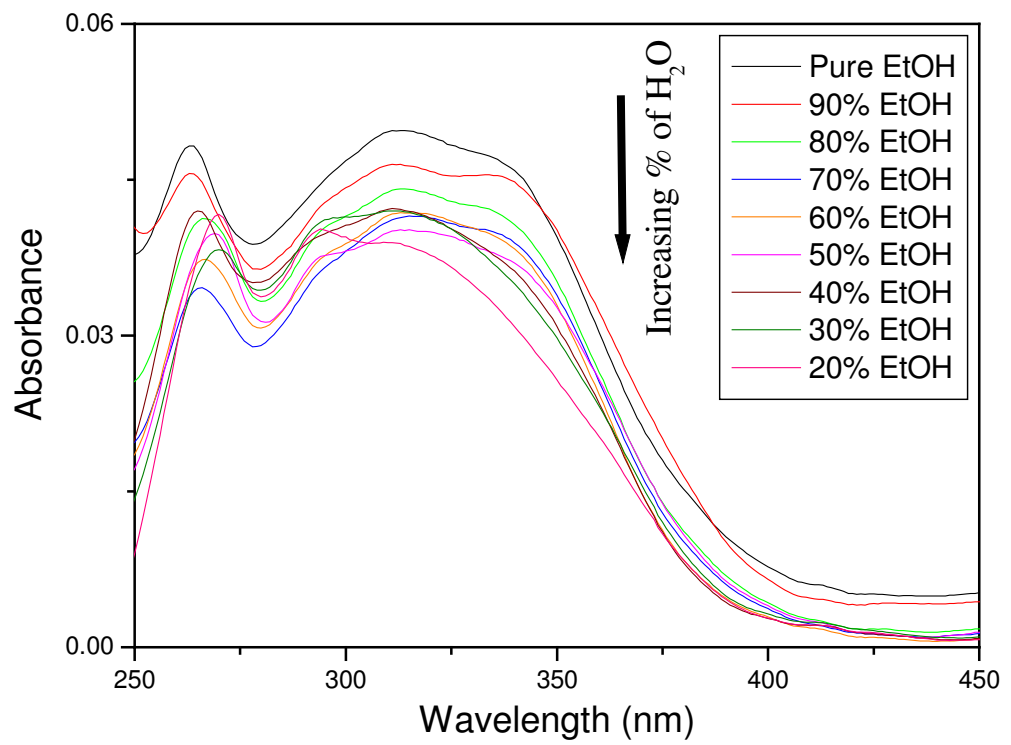

Figure S4. Uv-Vis spectra of compound 1 in different ratio (v/v) of water/ethanol mixture (JASCO, V-570, UV/VIS/NIR/ Spectrophotometer). 


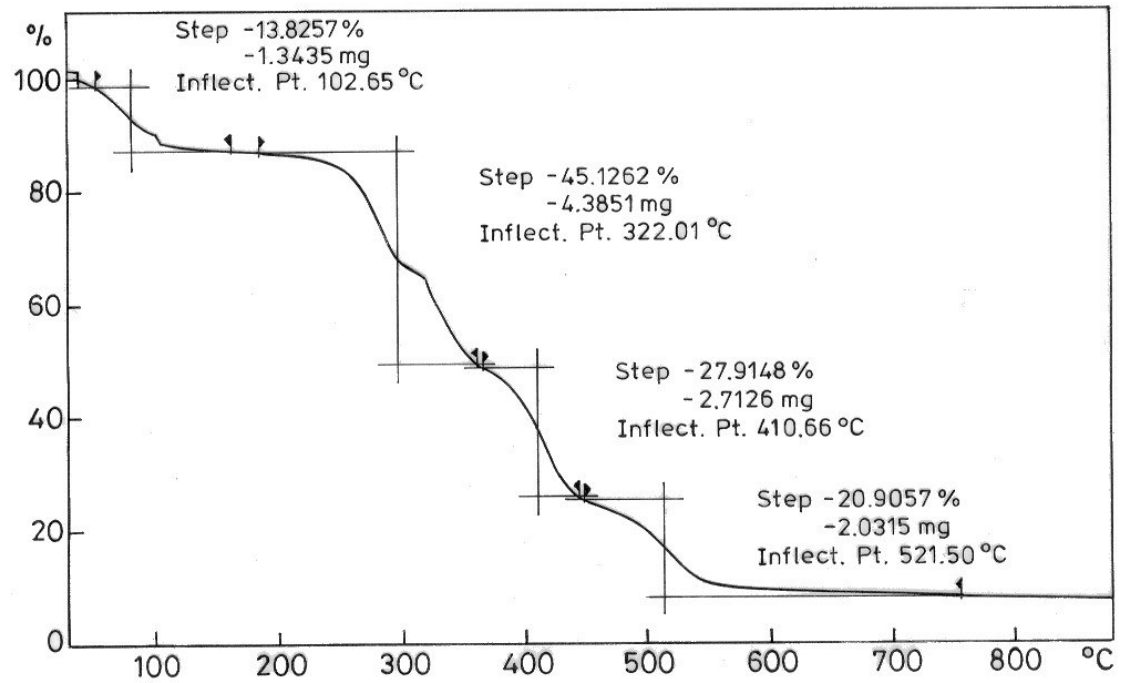

Figure S5. TGA spectra of compound 3.

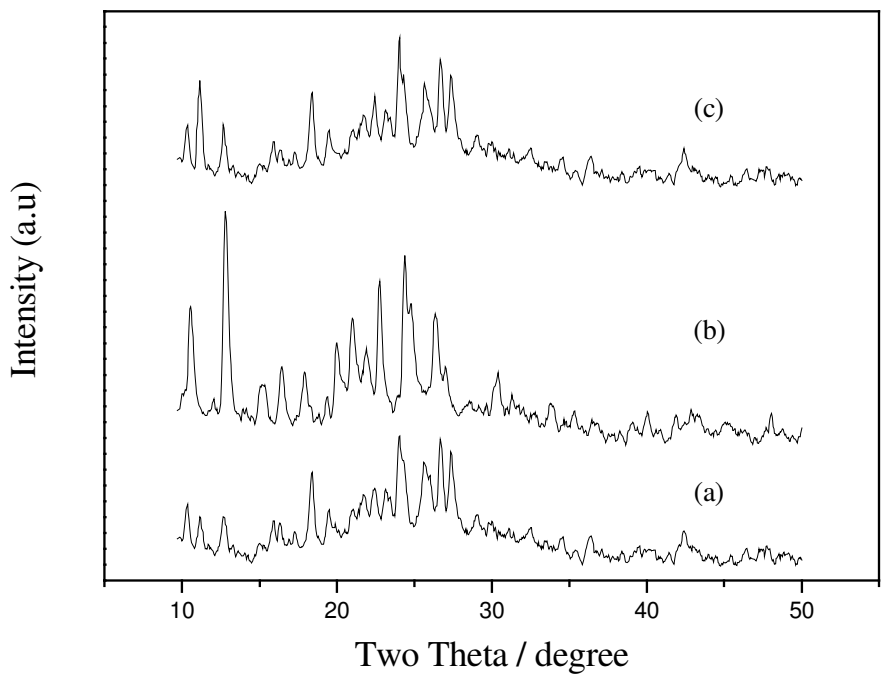

Figure S6: X-ray powder diffraction spectra of compound 1: (a) hydrated condition (b) de-hydrated upon heating at $110{ }^{\circ} \mathrm{C}$ for $1 \mathrm{~h}$ and (c) re-hydrated condition. 


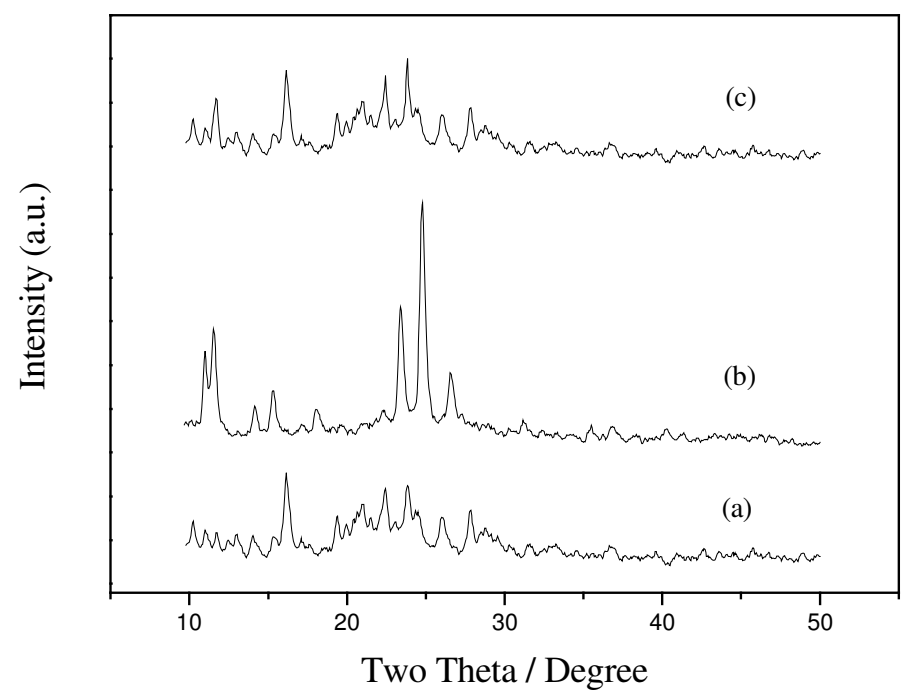

Figure S7: X-ray powder diffraction spectra of compound 2: (a) hydrated condition (b) de-hydrated upon heating at $100{ }^{\circ} \mathrm{C}$ for $1 \mathrm{~h}$ and (c) re-hydrated condition.

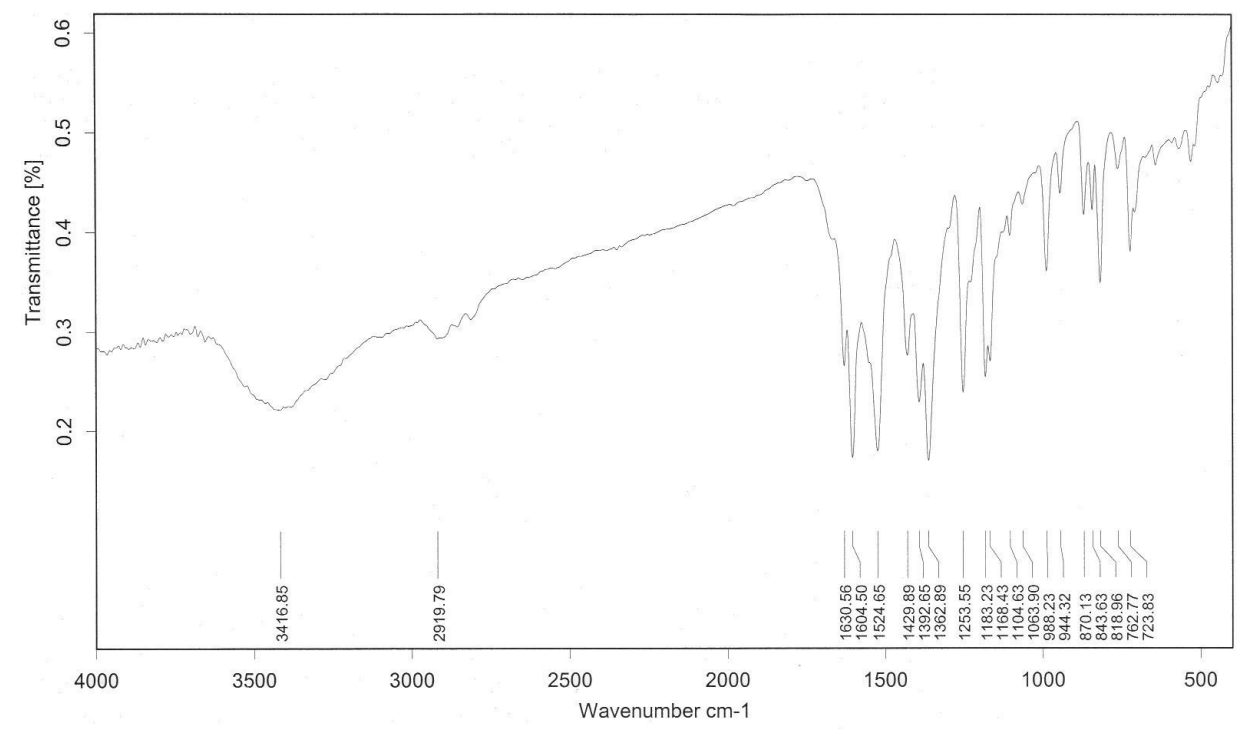

Figure S8. FTIR spectra of compound 3. 


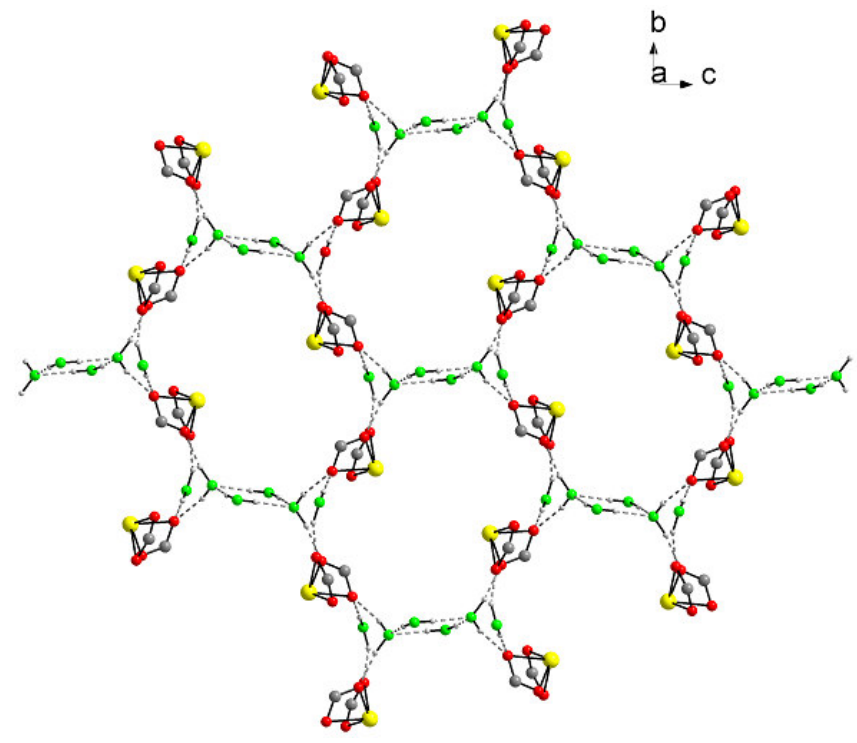

Figure S9. A simplified view of the tetrameric water clusters in the crystal lattice of 3.

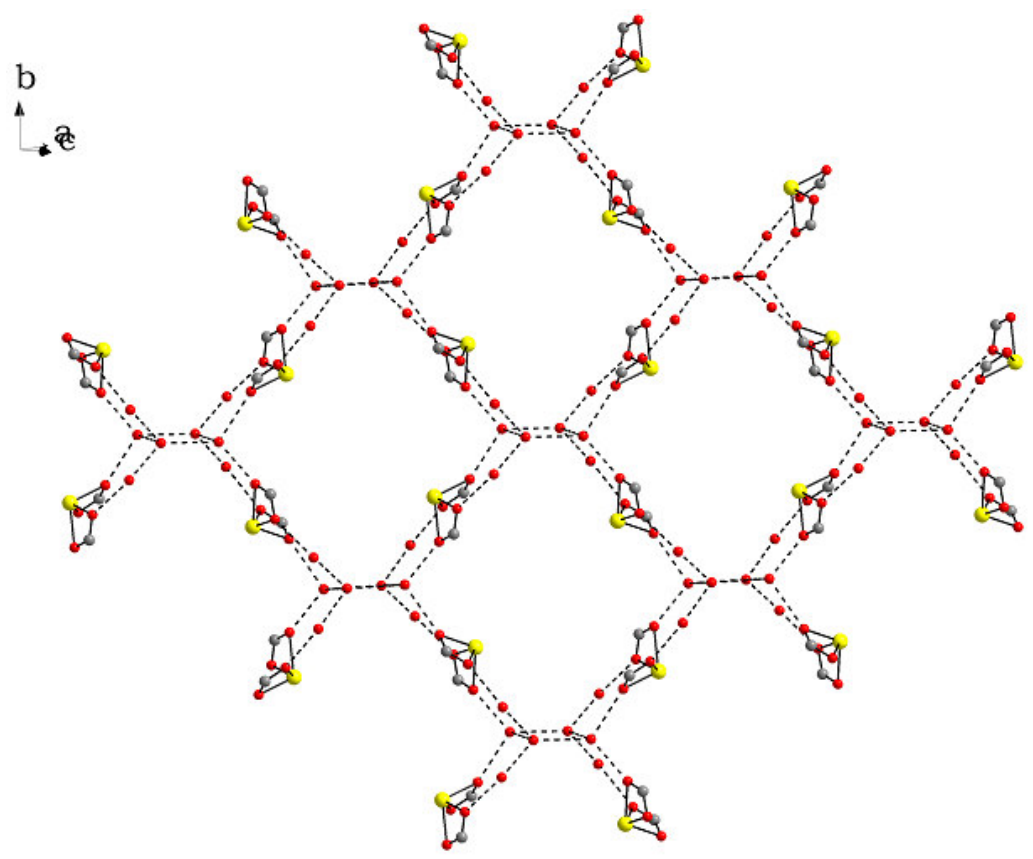

Figure S10. A simplified view of the octameric water clusters in the crystal lattice of 4. 


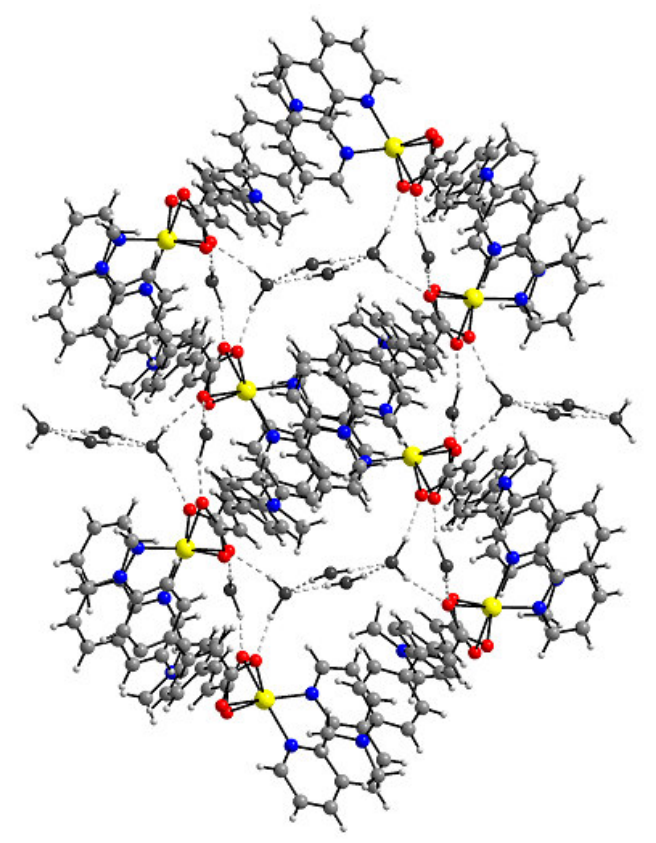

Figure S11. Building of the tetrameric water clusters in $\mathbf{3}$ viewed in the crystallographic $b c$ plan. Ethanol molecules are omitted and only carboxylate parts of the $d c a$ units are shown for clarity.

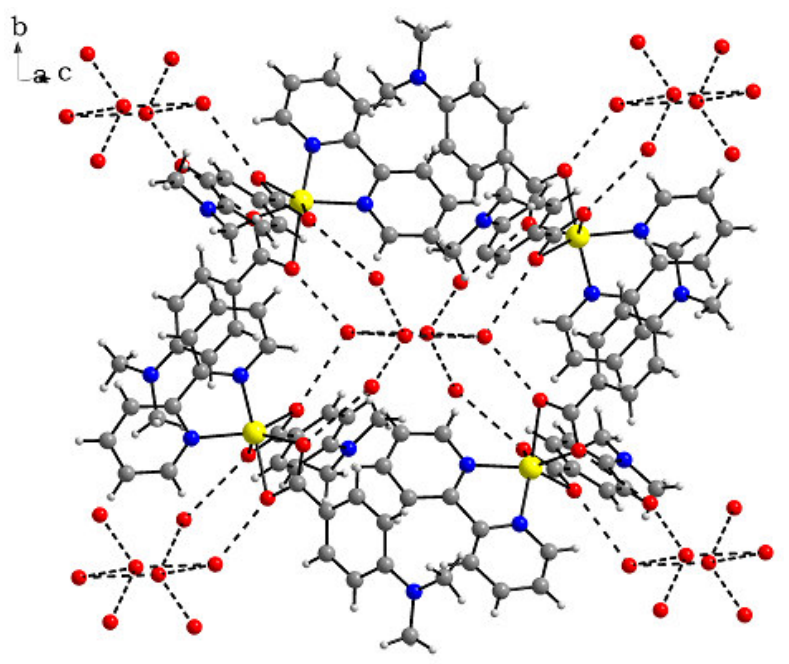

Figure S12: The mode of binding of octameric water clusters in 4 viewed approximately in the crystallographic $b c$ plan. 


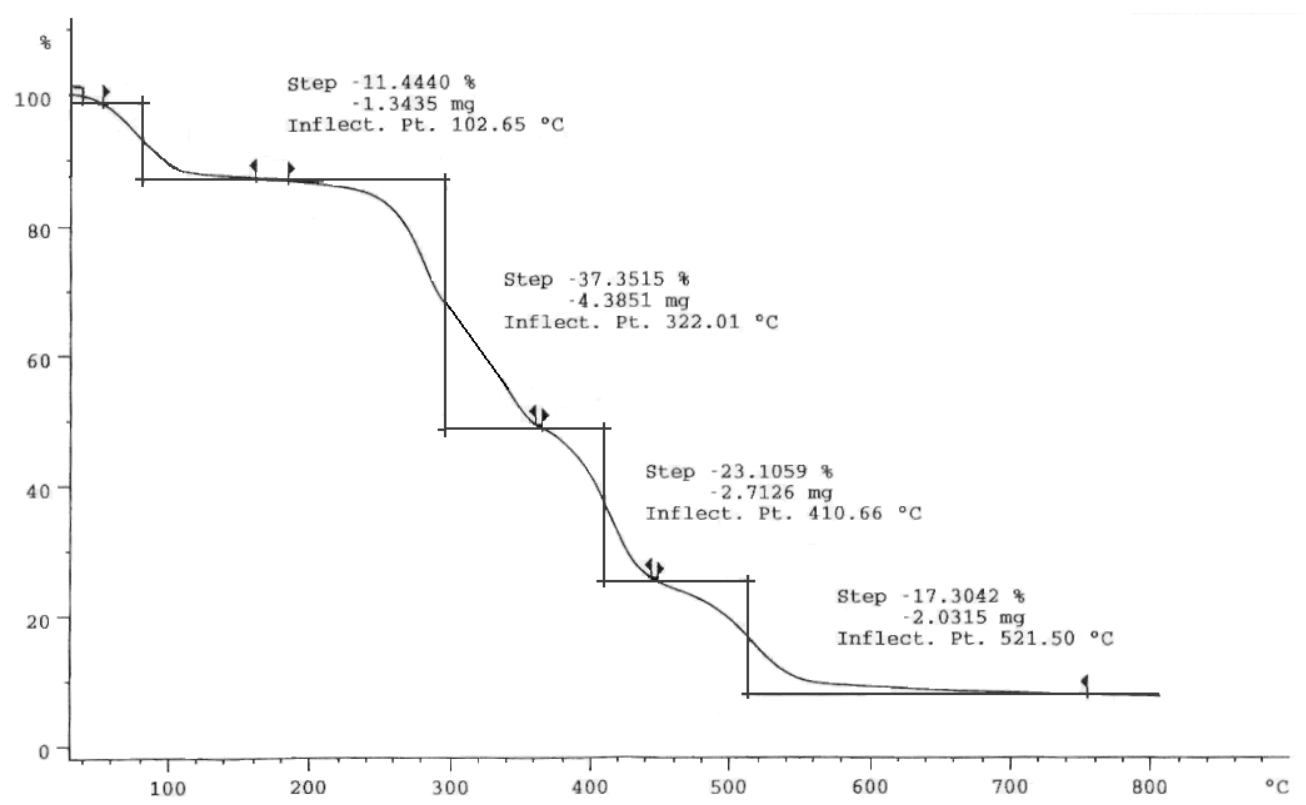

Figure S13. TGA spectra of compound 4.

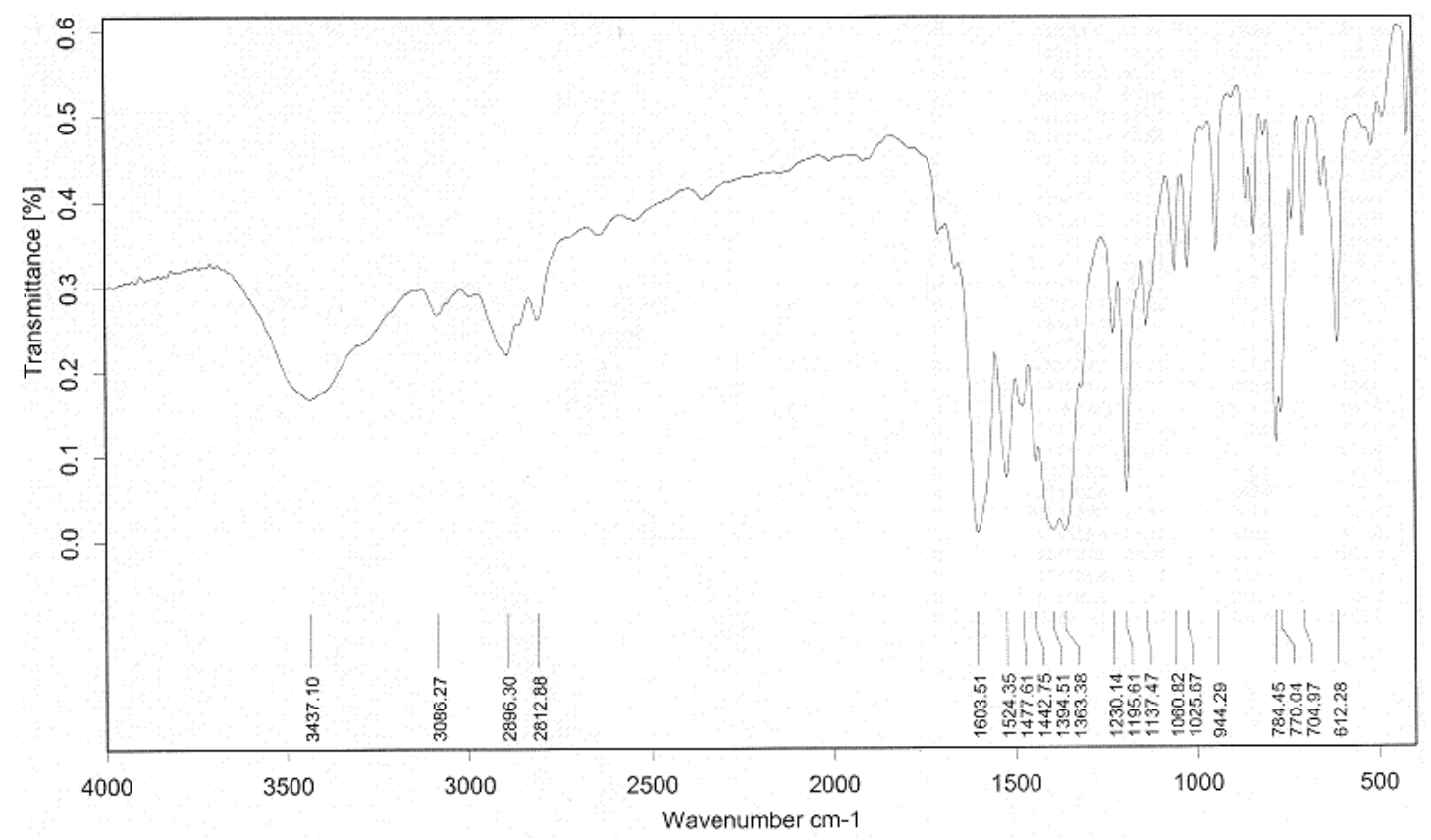

Figure S14. FTIR spectra of compound 4. 


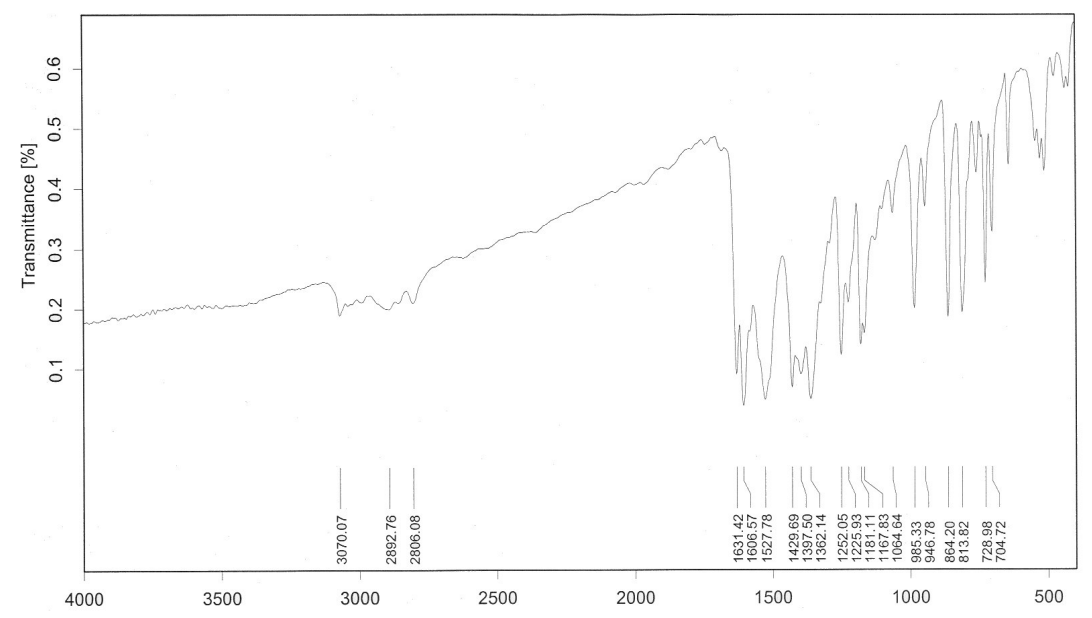

Figure S15. FTIR spectra of compound 1.

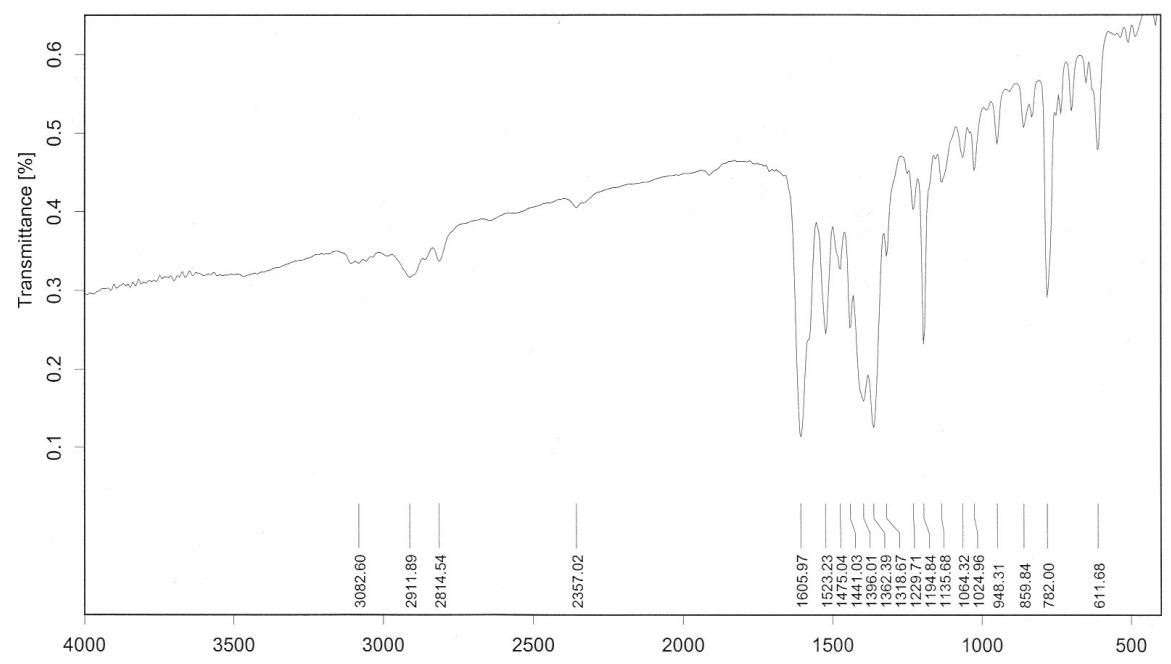

Figure S16. FTIR spectra of compound 2. 


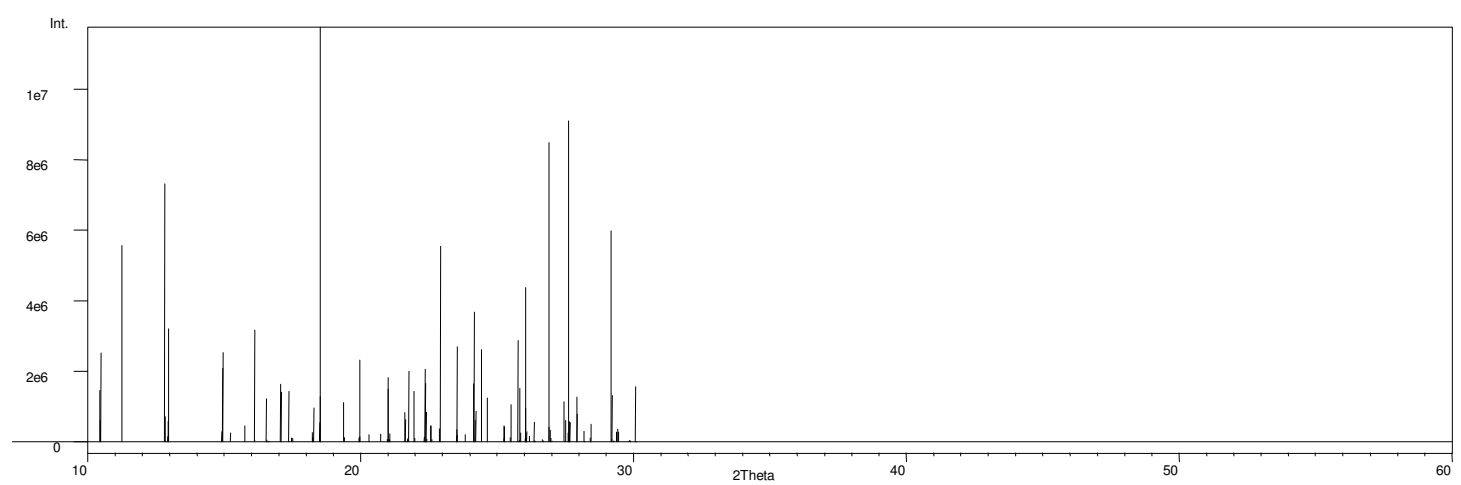

Figure S17. Calculated XRD pattern of Compound $\mathbf{3}$

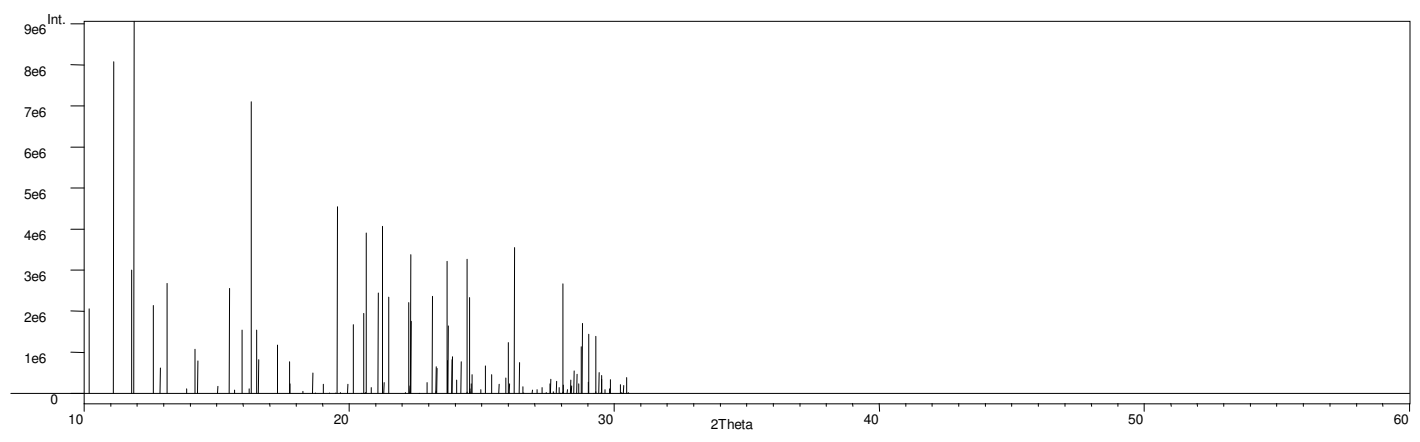

Figure S18. Calculated XRD pattern of Compound 4 